\title{
Parametric Analysis of Structural Noise of Steel-Concrete Composite Slab Beams
}

\author{
Xiao Liu, ${ }^{1}$ Nan Zhang $\mathbb{D}^{1},{ }^{1}$ Qikai Sun $\mathbb{D}^{,},{ }^{1}$ Kunpeng Wang $\mathbb{D}^{2},{ }^{2}$ and Zhaozhi Wu $\mathbb{D}^{1}$ \\ ${ }^{1}$ School of Civil Engineering, Beijing Jiaotong University, Beijing 100044, China \\ ${ }^{2}$ CCCC Highway Bridges National Engineering Research Centre Co., Ltd., Beijing 100120, China
}

Correspondence should be addressed to Nan Zhang; nzhang@bjtu.edu.cn

Received 15 October 2021; Accepted 10 February 2022; Published 7 March 2022

Academic Editor: Chao-Ping Zang

Copyright $\odot 2022$ Xiao Liu et al. This is an open access article distributed under the Creative Commons Attribution License, which permits unrestricted use, distribution, and reproduction in any medium, provided the original work is properly cited.

In this study, the vibration acceleration and radiation structure noise in specific points, $30 \mathrm{~cm}$ away from the center surface of each plate of the concrete deck, web, and flange of the steel beam, are measured via the hammering test. The test is conducted on the middle concrete deck of an $8.5 \mathrm{~m}$ steel-concrete composite slab beam. The accuracy of the numerical model is then carefully justified. The influence of the number of shear studs, spacing, and arrangement of ribs on the concerning results is methodically examined and discussed by employing the numerical model. In the center frequency of $10-1000 \mathrm{~Hz}$, the total sound power level of the structure can be lessened by improving the concrete deck thickness as well as the number of shear studs. The reduction of the rib spacing can effectively lessen the sound power level as well. The noise reduction of the plate with rib arrangement in the midspan zone is more influential than the case with uniform layout in the whole span.

\section{Introduction}

A steel-concrete composite plate beam (SCCPB) is commonly in connection with shear connectors to appropriately merge the concrete deck and steel girders, which provides many advantages and has been broadly exploited in recent years. One of the main problems in steel-concrete composite beam structures is that the vibration and noise caused by the excitation are significantly higher than those of the concrete beam. The structure-borne noise cannot be effectively reduced by employing the sound barrier. Therefore, it is necessary to find a way to suppress the vibration and radiation structure-borne noise of the steel-concrete composite beam. Many research works and noise prediction have been carried out in literature [1,2], which give insights into the theoretical analysis of noise. Based on the statistical energy principle, the paper aims to examine the structureborne noise of SCCPBs. The obtained results revealed that the web of the steel beam is the main radiation source of structure-borne noise, with a contribution rate of more than $50 \%$, and the frequency band of the structural noise was generally in the range of $125-1250 \mathrm{~Hz}$ [3]. Based on the statistical energy method [4], the authors proposed a method for calculating structure-borne noise of steel-concrete composite beam bridges subjected to vehicle-induced vibrations. The calculation model was verified by the test results [5]. It was noticed that the main frequency band of the structure-borne noise of the studied composite beam bridge would be between $20 \mathrm{~Hz}$ and $1000 \mathrm{~Hz}$, and the noise contribution of the flange was reported as the lowest in the analysis frequency band, and the bridge deck and steel beam web were mainly responsible for the frequency range below $315 \mathrm{~Hz}$, while the web mainly corresponds to the frequency band above $315 \mathrm{~Hz}$. The structure-borne noise of a steel truss composite beam and the contribution of each component were analyzed, and it was concluded that the longitudinal, the cross beam, and the main truss are the main noise sources [6]. A calculation model for the sound and vibration of railway composite beam bridge was also proposed [7]. After laying a constrained damping layer on a continuous SCCPB, the sound and vibration values in the analysis of frequency band were reduced to varying degrees. The field vibration and noise of a three-span continuous steel-concrete composite beam on Qinhuangdao-Shenyang passenger 
dedicated line were measured, and the spectrum characteristics as well as the sound field distribution of vibration and noise of the SCCPB were analyzed [8]. The results showed that when the train speed was $192 \mathrm{~km} / \mathrm{h}$, the main frequency band of vibration acceleration of the plate was in the range of $50-1000 \mathrm{~Hz}$, and the response plot takes its peaks at the frequency values of $63 \mathrm{~Hz}$ and $80 \mathrm{~Hz}$. The main frequency band of the structure-borne noise was placed in the frequency interval of 20 and $1000 \mathrm{~Hz}$, which is essentially related to the force transmitted on the bridge deck.

So far, fewer works have been devoted to the vibration and noise reduction in SCCPBs. The influences of the crosssection size and material parameters on the radiated structure-borne noise of steel bridges have been studied by establishing the finite element FE-SEA hybrid model [9]. The noise reduction effect of the concrete deck on the steel beams was studied by beam and web hammering tests. The test results revealed that adding a concrete deck can reduce the vibration transmitted from the deck to the steel beam, resulting in a modification of the stiffness and damping of the structure [10]. For steel-concrete composite beams, the most crucial components are shear connectors (main shear studs). According to $[11,12]$, the theoretical and experimental analyses of six SCCPBs with various shear stud connections showed that the stiffness of the stud affects the global stiffness and natural frequencies of the composite beam. The natural vibration characteristics of SCCPBs were analyzed by utilizing the finite element method and combining that with specific examples $[13,14]$. The obtained results indicated that with the increase of order, the discrepancies between the results of the numerical simulations and the theoretical results become greater. Some scholars analyzed the load transfer mechanism through field tests [15], proposed a multilayer modeling method [16], established a composite finite element model [17], explored the elastic buckling of thin plates under various boundary conditions [18], and analyzed the influence of structural dimensions, boundary conditions, and other parameters on the natural frequency of the structure [19]. In the present paper, the effects of the structural design parameters, number of shear studs, spacing, and arrangement of ribs on the radiated sound power level of SCCPBs will be investigated and discussed by employing the verified numerical model. Also, the harmonic response analysis method is used under the hammering force in the frequency domain to obtain the vibration response, which serves as the boundary condition for the BEM. It avoids the time-frequency conversion, reduces the amount of calculation, and improves the calculation efficiency. At the same time, it provides ideas for the noise reduction design of steel-concrete composite plate beams.

\section{Experimental Verification}

2.1. Experimental Girder. The understudy experimental object is a simply supported SCCPB with a span of $8.5 \mathrm{~m}$. The utilized concrete is C50, and the steel material is $\mathrm{Q} 345 \mathrm{qE}$. The ribs at the support are tightly compacted with the upper flange and welded with the lower flange.. The section dimensions of the SCCPB and the arrangement of shear studs are presented in Figures 1(a) and 1(b). The width and height of the concrete deck in order are $1.7 \mathrm{~m}$ and $0.3 \mathrm{~m}$. The width of both the upper and lower flanges is $0.45 \mathrm{~m}$, while their thickness and height are $28 \mathrm{~mm}$ and $0.606 \mathrm{~m}$, respectively. The field test beam is illustrated in Figure 2.

2.2. Test Description. The impact test has been utilized to excite the composite plate beam. The force, response acceleration, and sound pressure signal are recorded [20]. The measuring points are arranged in the midspan section, and the sound pressure sensor is vertically arranged at a distance of $30 \mathrm{~cm}$ from the surface of each plate. The concrete deck in the middle span is vertically excited by hammering, as demonstrated in Figure 3. The maximum measuring load is $300 \mathrm{kN}$, and the vibration acceleration sensor is made from a piezoelectric material with an accuracy of $10 \mathrm{~g}$ and a frequency range of $0.35-4000 \mathrm{~Hz}$. The sound pressure sensor is MPA231. The test equipment is presented in Figure 4. In order to induce the high-frequency vibration of the test beam, the steel hammer was utilized, and the sampling frequency was set equal to $10.24 \mathrm{kHz}$. Four hammers were employed for the sake of avoiding the contingency of the extracted data, and each pause is set to $30 \mathrm{~s}$ to ensure the integrity of individually applied vibration.

The hammering force, vibration acceleration, and sound pressure in both time and frequency domains of a single test are demonstrated in Figure 5. It can be seen that the hammer could effectively stimulate high vibrations in the range of $10-1000 \mathrm{~Hz}$, and the validity of the data in this frequency interval was proved. The vibration acceleration and sound pressure in the time domain have obvious attenuation characteristics, and their corresponding peaks in order are about $3.5 \mathrm{~m} / \mathrm{s}^{2}$ and $0.6 \mathrm{~Pa}$. The vibration acceleration of the concrete deck and the flange in the frequency domain are basically the same; however, the peak acceleration of the concrete deck is in the range of $20 \sim 200 \mathrm{~Hz}$, while that of the flange of the steel beam and the web in order is $20-1000 \mathrm{~Hz}$ and $400-1000 \mathrm{~Hz}$. The maximum sound pressures of the concrete deck and steel beam flange occur in the range of $20-500 \mathrm{~Hz}$, while those of the web appear for the natural frequencies in the interval of $20-250 \mathrm{~Hz}$. Compared with the obtained results for the concrete girder, the vibration and noise frequency bands in the present work are generally wider.

\section{Numerical Model}

3.1. Establishment of the Model. The finite element model of the SCCPB is established. To obtain the local vibration of the concrete slab and I-shaped steel beam, the shell element is employed. The shear studs are modeled by the beam elements of steel with a cylindrical section to ensure that the energy can be effectively transmitted from the concrete deck to the steel beam. The internal loss factor of steel is 

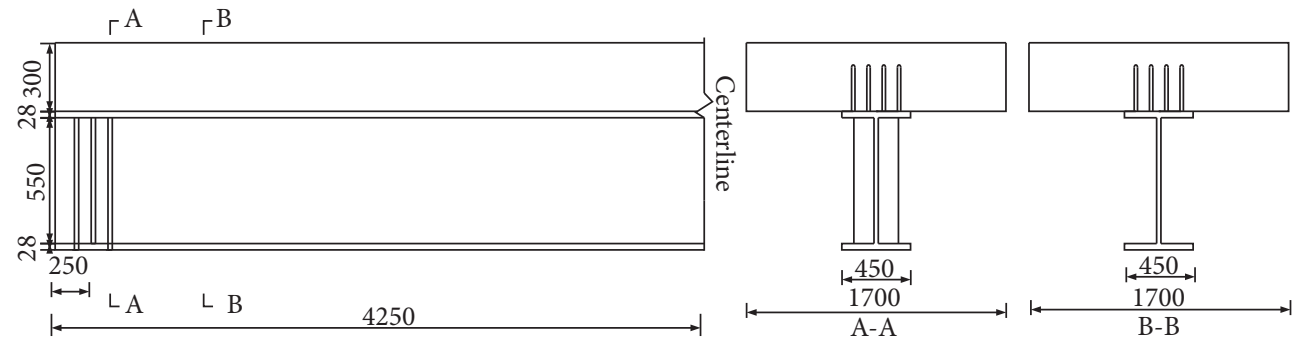

(a)

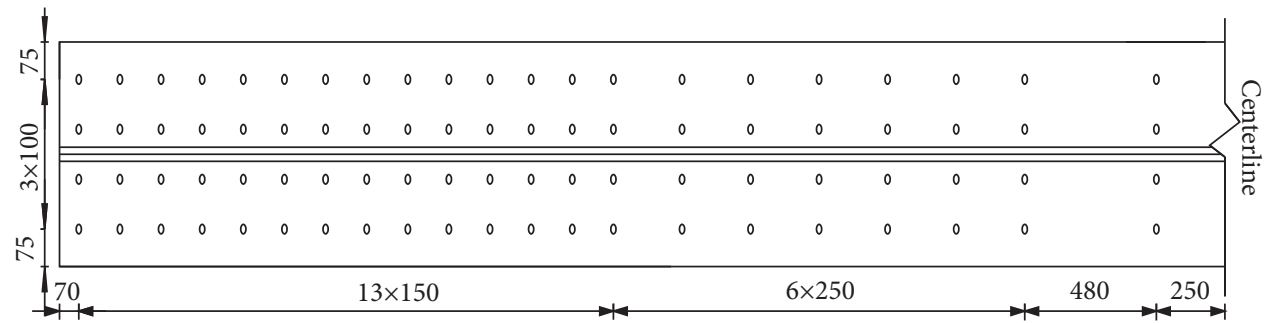

(b)

Figure 1: The section dimensions and shear stud arrangement of the SCCPB. (a) Section dimensions (mm). (b) Shear stud arrangement $(\mathrm{mm})$.

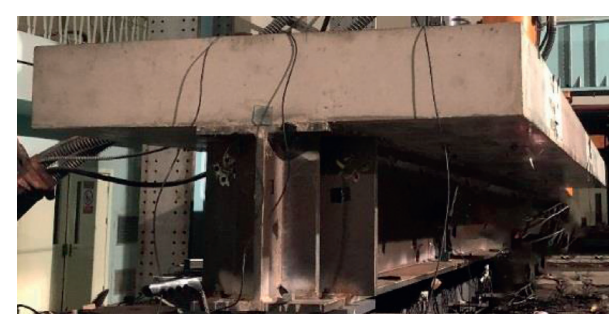

FIgURE 2: The field test beam.

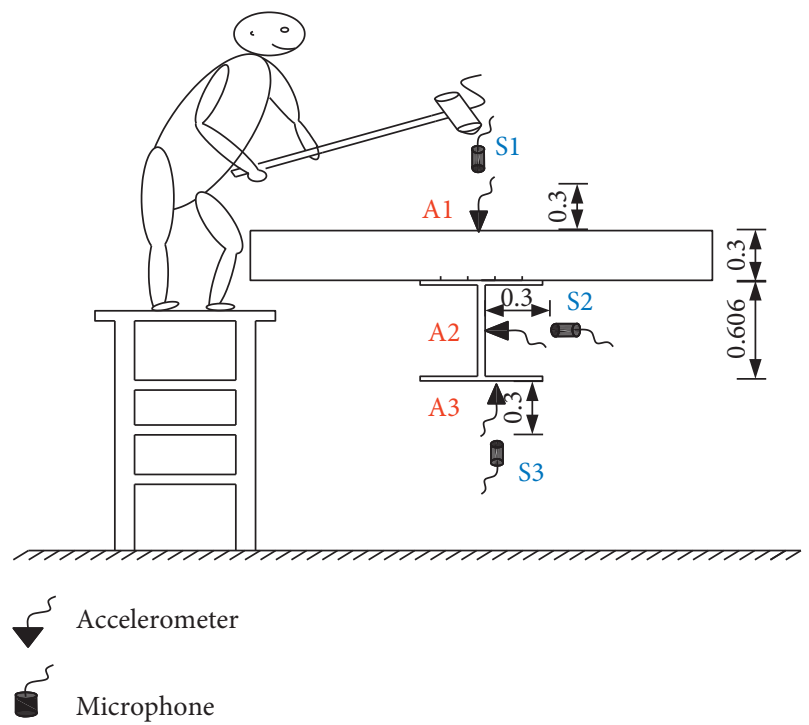

Figure 3: Schematic representation of the hammering test and measuring point arrangement.

$0.1 \%$ while that of concrete is $1.5 \%$. The boundary conditions of the main structural members have simply supported constraints. The length of the consisting elements must be lower than $1 / 6$ of the shortest wavelength of the calculation frequency [21]. In the present work, the frequency is set to $1000 \mathrm{~Hz}$, and the length of the response element is smaller than $50 \mathrm{~mm}$. The total number of elements is about 18000, as demonstrated in Figure 6. Global mode describes the bending vibration to which the entire mass of the bridge contributes, while the local mode is for the bending vibration localized in a small area of the beam. The influence of the local mode on the radiated sound field close to the beam surface is greater than that of the global mode. Figure 7 shows the typical global and local mode of the SCCPB. It can be seen that the local mode is within the higher frequency band than the global one. This is why the frequency band of radiated noise of SCCPB is set to be wide for the research.

3.2. Model Validation. The hammering force in the frequency domain measured by one of the test is applied to the beam model. The vibration displacement of the beam model is obtained by the harmonic response analysis, regarded as the boundary conditions of the boundary element method (BEM). This paper analyzes the response of SCCPB in the frequency domain to explore its stationary characteristics, so the transient vibration at the beginning of excitation is not considered. The sound pressure of any field point can be evaluated by employing the BEM [22].

After one-third octave processing, the vibration acceleration and sound pressure level of each plate are appropriately calculated (see Figure 8). It can be seen from Figures $8(a)-8(c)$ that the global characteristics of the computed acceleration of each plate are consistent with those obtained from the test. The vibrations of the concrete deck and the flange are basically consistent; however, their 


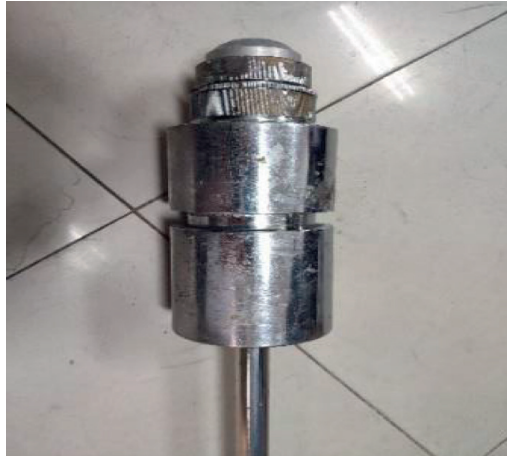

(a)

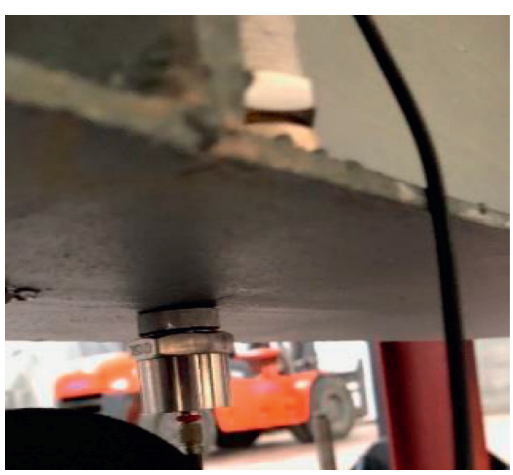

(b)

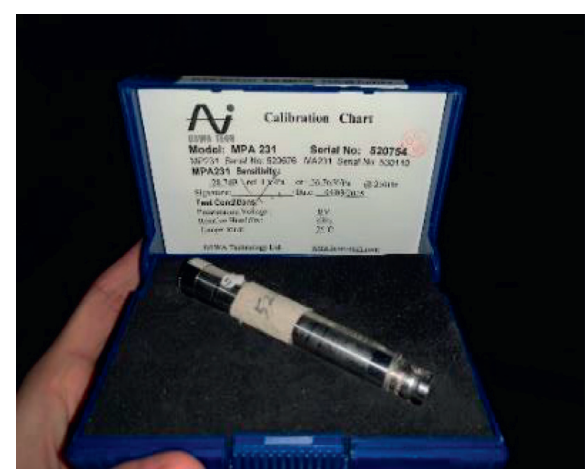

(c)

Figure 4: Test equipment. (a) Hammer. (b) Vibration acceleration sensor. (c) Sound pressure sensor.

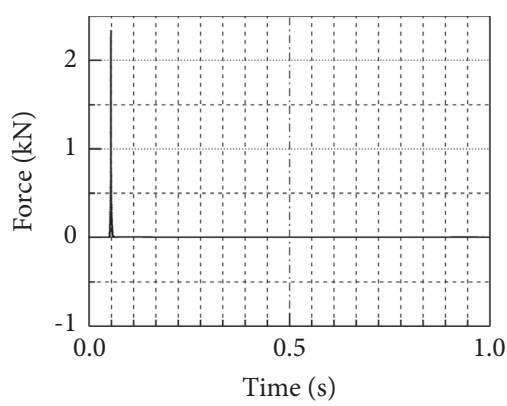

(a)

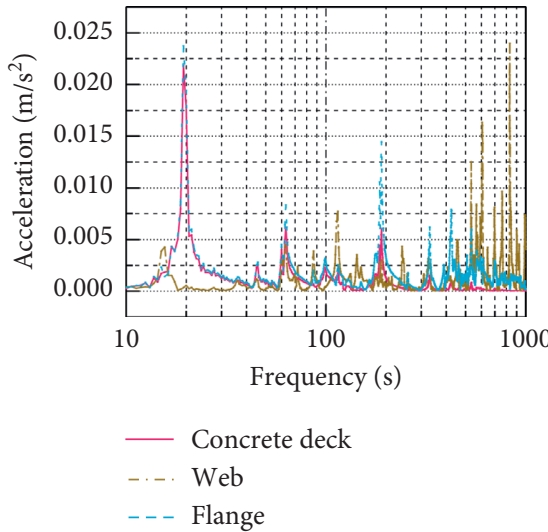

(d)
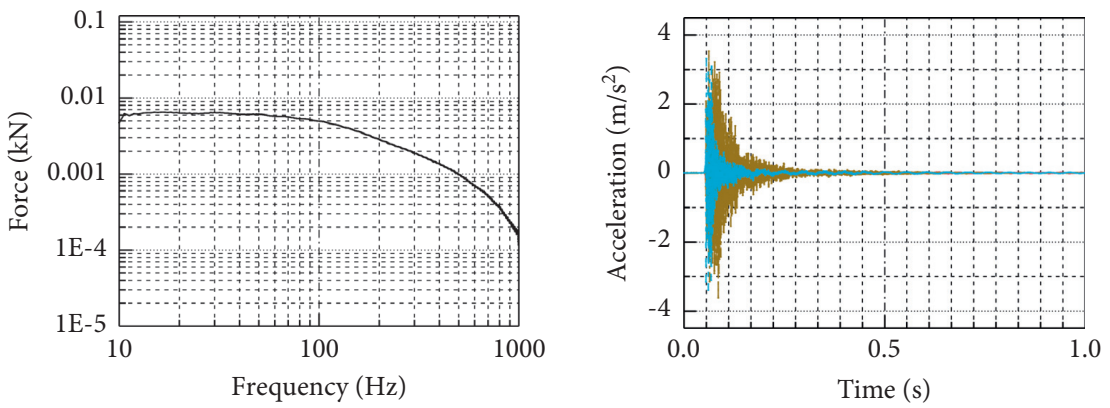

_- Concrete deck
-.. Web
_- Flange

(c)

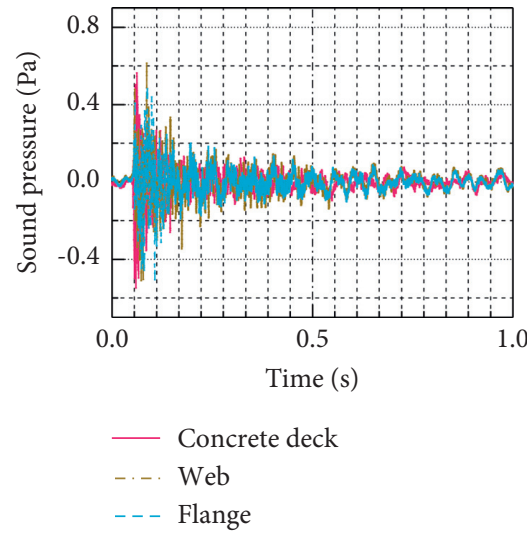

(e)

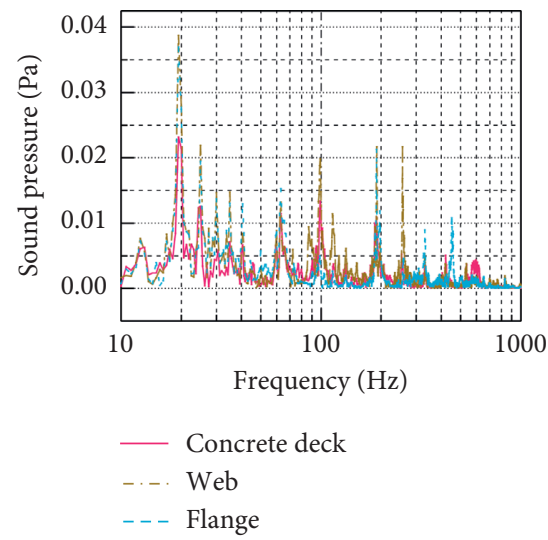

(f)

Figure 5: The measured data from one hammering. (a) Force (time domain). (b) Force (frequency domain). (c) Acceleration (time domain). (d) Acceleration (frequency domain). (e)Sound pressure (time domain). (f) Sound pressure (frequency domain).

high-frequency plots have obvious attenuation compared with those of the flange. The web vibration exhibits more portion of the high-frequency part. Figures $8(\mathrm{~d})-8(\mathrm{f})$ demonstrate the comparison between the calculated sound pressure levels at the corresponding position and those obtained from the test. It can be observed that the frequency characteristics are similar, and there are some discrepancies only at individual frequency points. To sum up, the calculation model has particular reliability.

\section{Parametric Analysis}

The influences of the structural design parameters, variation of the thickness of the concrete deck, number of shear studs, spacing, and arrangement of ribs on the sound radiation characteristics are discussed in the presence of the excitation force of $100 \mathrm{~N}$ in the frequency range of $10-1000 \mathrm{~Hz}$ at the center of the concrete deck. The sound power level is employed to characterize the sound 


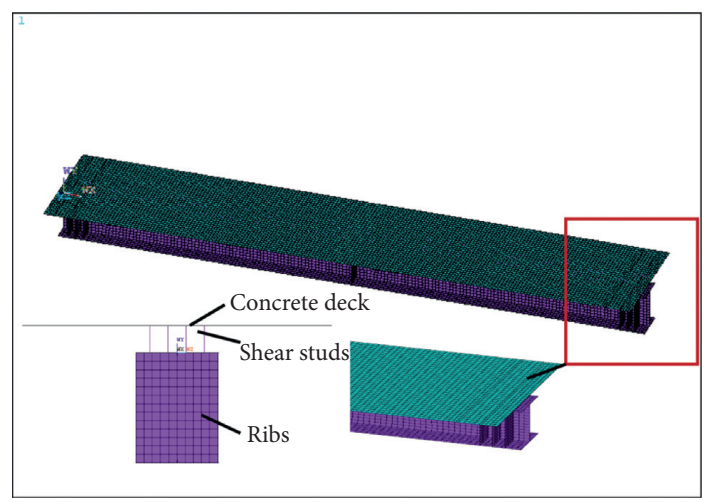

Figure 6: The constructed FE-based SCCPB model.

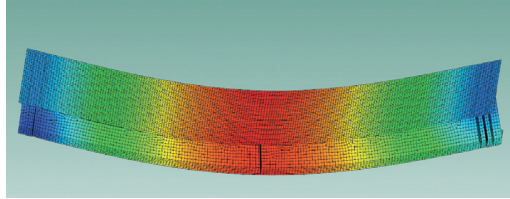

$\mathrm{f}_{1}=17.428 \mathrm{~Hz}$

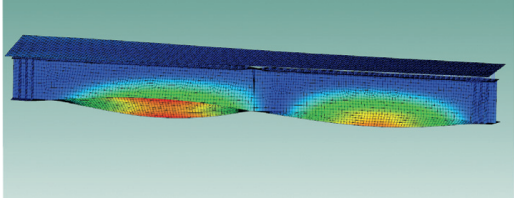

$\mathrm{f}_{9}=76.79 \mathrm{~Hz}$

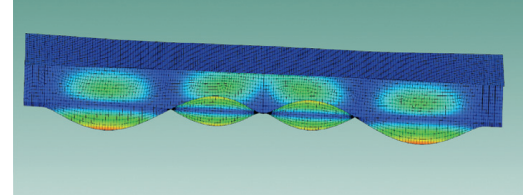

$\mathrm{F}_{20}=181.31 \mathrm{~Hz}$

Figure 7: Several vibrational modes.
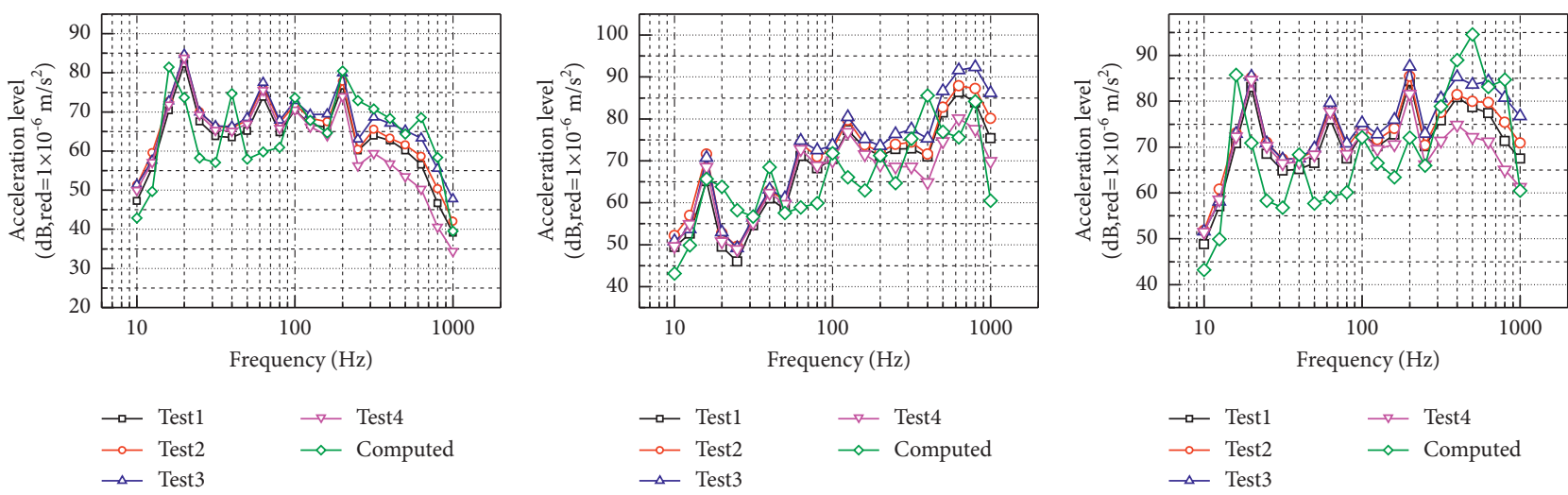

(a)
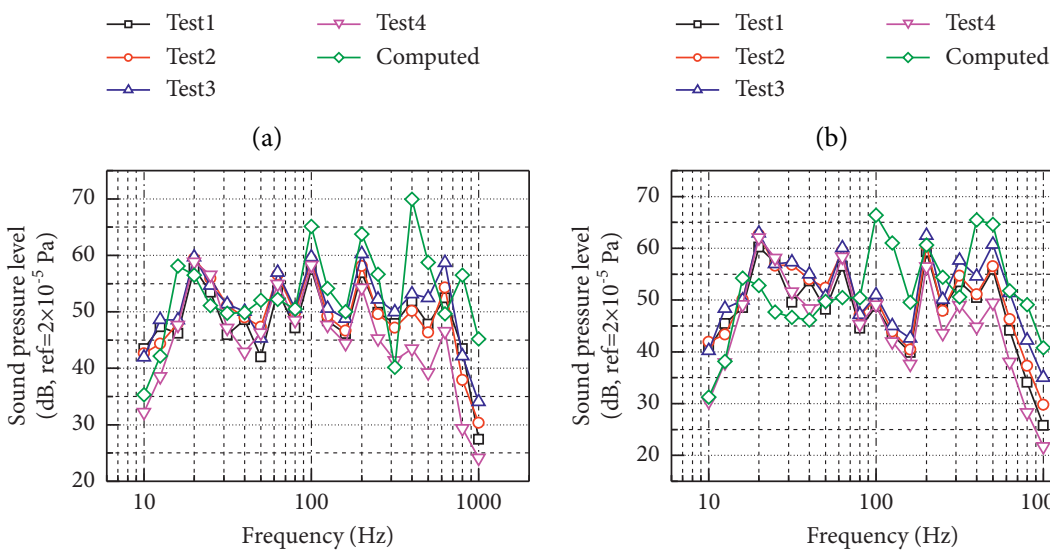

(b)

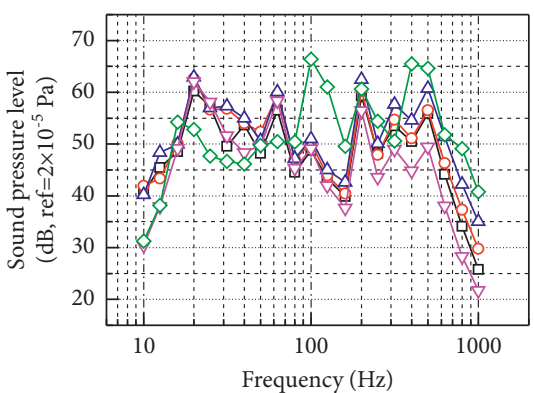

$$
\begin{aligned}
& \rightarrow \text { Test1 } \\
& \rightarrow \text { Test4 } \\
& \begin{array}{ll}
\longrightarrow & \text { Test2 } \\
\longrightarrow & \text { Test3 }
\end{array} \\
& \rightarrow \text { Computed }
\end{aligned}
$$

(d)

$$
\begin{array}{ll}
\rightarrow-\text { Test1 } & \rightarrow \text { Test4 } \\
\multimap \text { Test2 } & \neg \text { Computed } \\
\neg-\text { Test3 } &
\end{array}
$$

(e)

$$
\begin{aligned}
& \begin{array}{ll}
\longrightarrow & \text { Test1 } \\
\longrightarrow & \text { Test2 }
\end{array} \\
& \rightarrow-\text { Test } 4
\end{aligned}
$$$$
\triangle \sim \text { Test3 }
$$

(c)

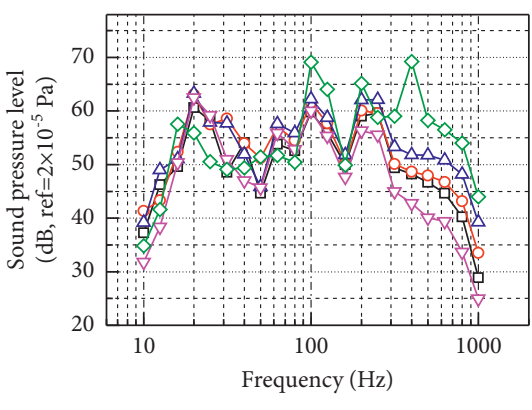

$$
\begin{array}{ll}
\rightarrow-\text { Test1 } & \rightarrow \text { Test4 } \\
\rightarrow \text { Test2 } & \rightarrow \text { Computed } \\
\rightarrow-\text { Test3 } &
\end{array}
$$

(f)

Figure 8: Comparison between the computed and test values of the acceleration and sound pressure at the measuring points. (a) A1. (b) A2. (c) A3. (d) S1. (e) S2. (f) S3. 


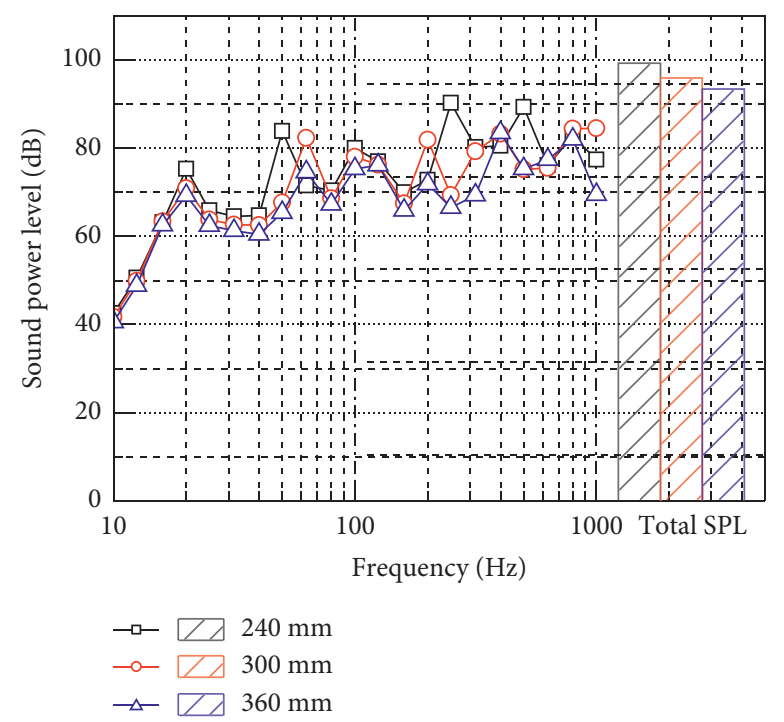

FIgURE 9: Variation of the sound power level in terms of the thickness of the concrete slab.

radiation ability of the structure. Unlike the sound pressure level, the sound power is irrelevant to the position of the field point. The calculation formula is as follows [23]:

$$
P=\rho c \sum_{j} \sigma_{j} S_{j}\left(v_{j}^{2}\right)
$$

where $\sigma_{j}$ is the radiation efficiency of the plate, which relies on the wavelength, structure dimensions, and shape of vibration modes. The factors $S_{j}$ and $v_{j}^{2}$ denote the area and vibration energy of the plate. The reference sound power level can be expressed by $P_{0}=1 \times 10^{-12} \mathrm{~W}$.

4.1. Influence of the Concrete Deck Thickness. The thickness of the concrete deck is taken as $240 \mathrm{~mm}, 300 \mathrm{~mm}$, and $360 \mathrm{~mm}$ for further calculations and analyses, while other factors are kept fixed. The calculation results of the sound power level are presented in Figure 9. The total sound power level decreases from $3.2 \mathrm{~dB}$ to $2.4 \mathrm{~dB}$ as the thickness increases from $240 \mathrm{~mm}$ to $360 \mathrm{~mm}$. This fact clearly reveals that the structure-borne noise of the SCCPB can be reduced by growing the thickness of the concrete deck.

The variation of the concrete deck thickness alters the structure weight and rigidity. Further, the natural vibration characteristics of the combined beam change accordingly, resulting in the alteration of the mode contribution. Figure 10 demonstrates the plot of the natural vibration frequency of the beam as a function of the thickness of the concrete deck. It can be seen from Figure 10(a) that the first nine natural frequencies decrease with the increase of the plate thickness. It implies that the influence of quality on the vibrational frequency is stronger than the stiffness, and the damping ratio in the frequency band decreases with the increase of the frequency. According to Figure 10(b), the thicker plate results in a larger natural frequency of the structure, namely, the influence of the mass on the vibrational frequency is weaker than the rigidity, and the damping ratio in such a frequency band increases with the frequency. For the high-order natural vibration frequency, the local vibration of the plate is the dominant part.

4.2. Influence of the Shear Studs. Some numerical simulations are carried out to investigate the variation of the shear studs number on the noise. The arrangement of the shear studs is presented in Figure 11. The shear studs can not only prevent the vertical separation of the flange from the steel beam but also transfer the shear forces. Therefore, the position of the hammering test is considered at the transverse center of the concrete deck in the midspan point. Figure 12 reveals the structural sound power level for four kinds of the shear stud arrangement, in which Case 2 represents the test girder. It can be seen that the reduction of shear studs leads to decrease of the first peak frequency. When the number of shear studs decreases from 320 to 64, the total sound power level apparently increases, and the values of reduction are $6.5 \mathrm{~dB}$ and $2.8 \mathrm{~dB}$, respectively. It implies that a large number of shear studs can suppress the noise of the structure. Figure 13 presents the first 30 frequencies of various numbers of shear studs, and the natural frequency of the beam increases with the increase of the number of shear studs, which shows that shear studs can effectively increase the stiffness of the beam and reduce the local vibration of the beam.

4.3. Influence of the Rib Spacing and Arrangement. There are ribs in the middle and ends of the test beam. On this basis, the ribs with the same size and properties are added with different longitudinal levels of spacing to examine their effects. The considered spacing levels are 2125, 1415, 1062.50, 850 , and 531.25, and the corresponding number of ribs in order is $3,5,7,9$, and 25 (see Table 1). In addition, three and seven rib plates are evenly arranged in the midspan with a spacing of $700 \mathrm{~mm}$ to explore the influence of rib spacing and arrangement on the structural noise. The layout of the 


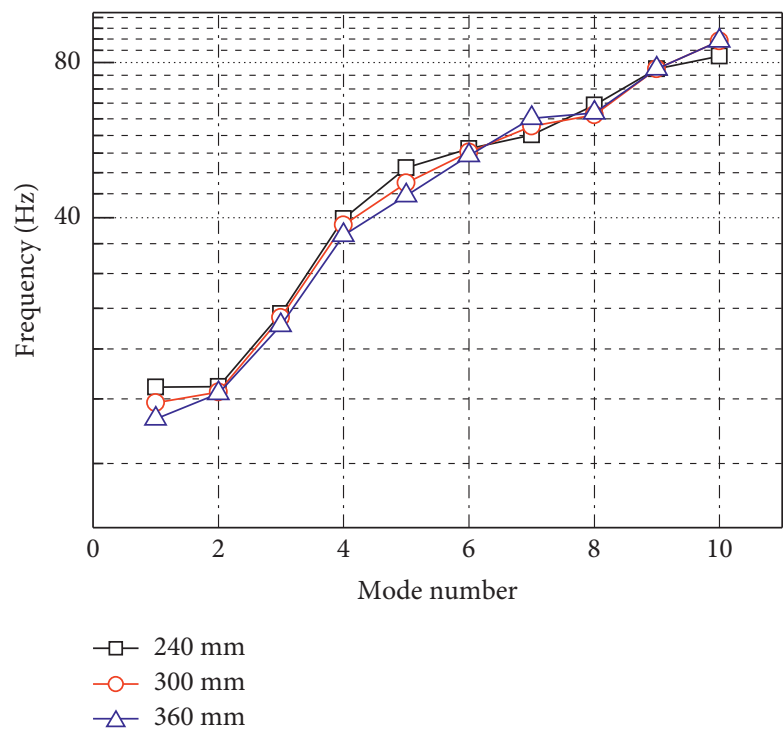

(a)

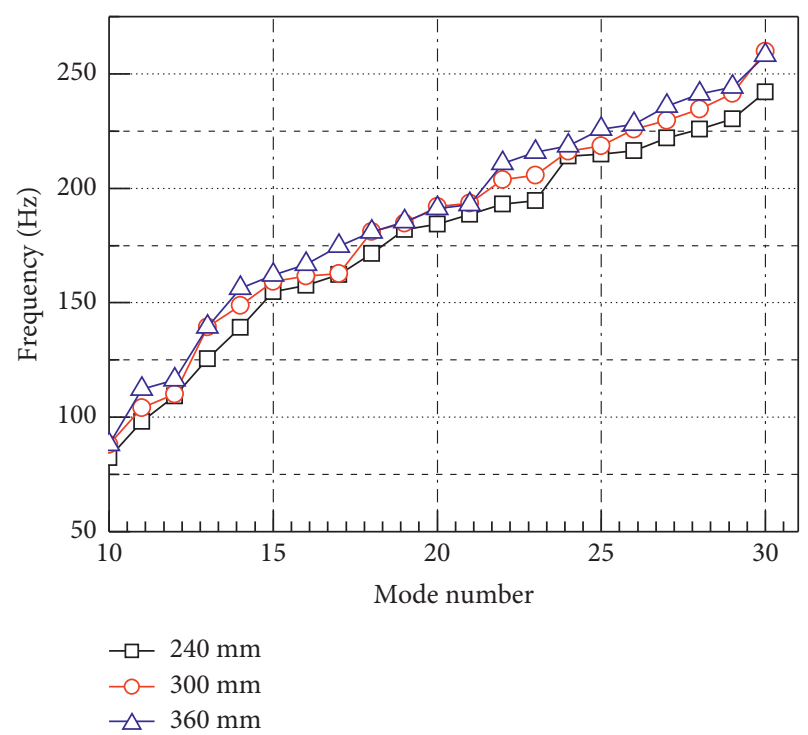

(b)

Figure 10: The first thirty natural frequencies for different values of the plate thickness. (a) The first ten natural frequencies. (b) Natural frequencies of various modes (10-30).

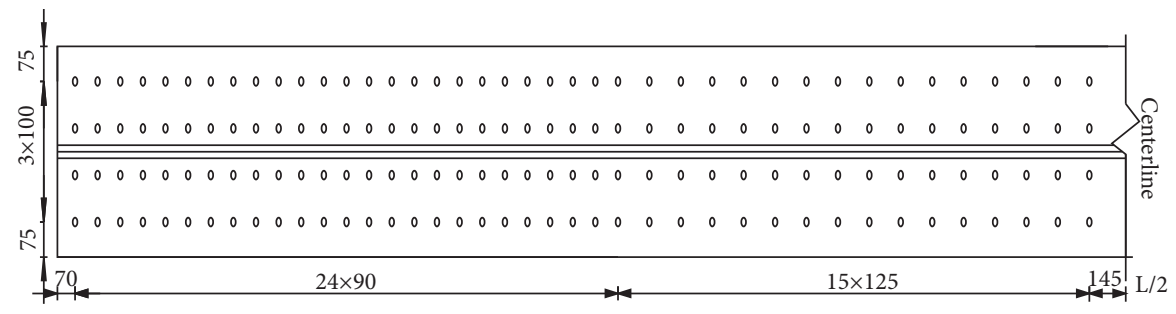

(a)

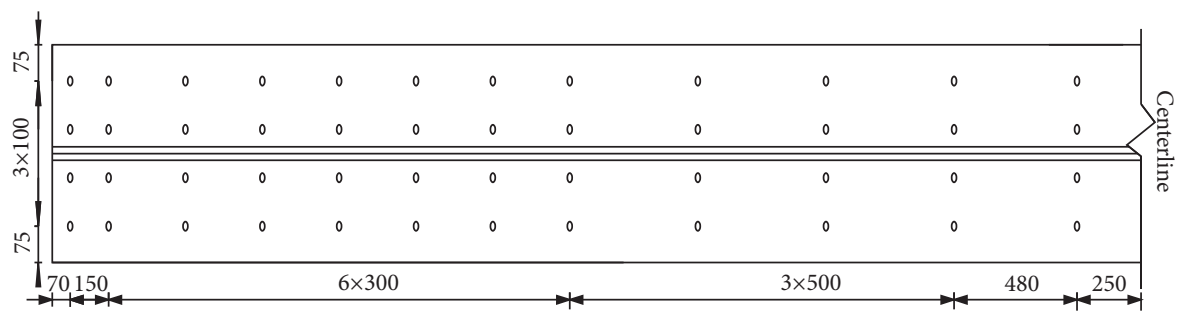

(b)

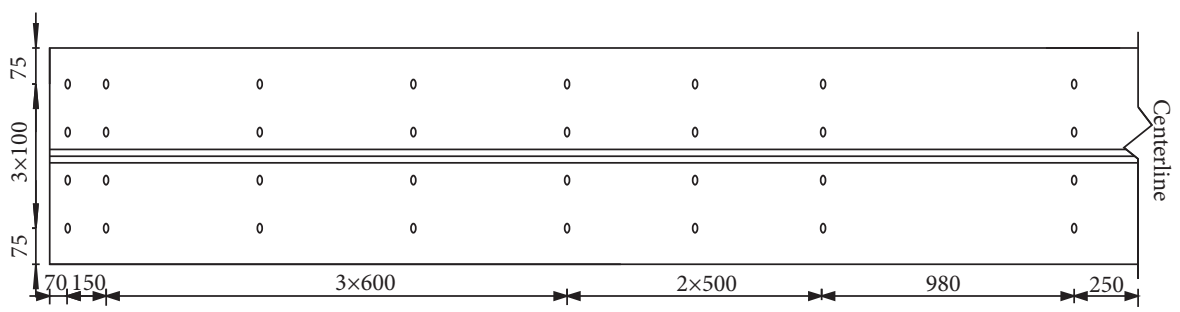

(c)

Figure 11: Different layouts of the shear studs. (a) Case1 (320). (b) Case 3 (96). (c) Case 4 (64).

rib is presented in Figure 14. When the excitation force of the same size and position is vertically exerted to the center of the midspan deck, the calculated sound power level is shown in Figure 15. It is apparently detectable that the total sound power level of the structure decreases first and then increases with the decrease of the rib plate spacing. When the rib plate spacing decreases from $2125 \mathrm{~mm}$ to $1062.5 \mathrm{~mm}$, the total sound power decreases by $4 \mathrm{~dB}$. The results show that the total sound power level increases by $3.2 \mathrm{~dB}$ when the longitudinal spacing reduces from $1062.5 \mathrm{~mm}$ to $531.25 \mathrm{~mm}$. 


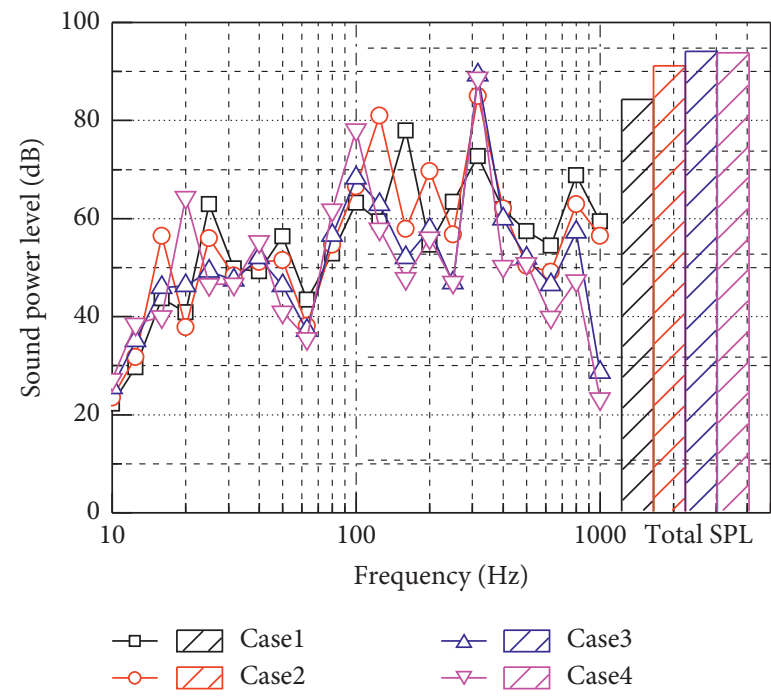

Figure 12: Plots of sound power level frequency for various numbers of shear studs.

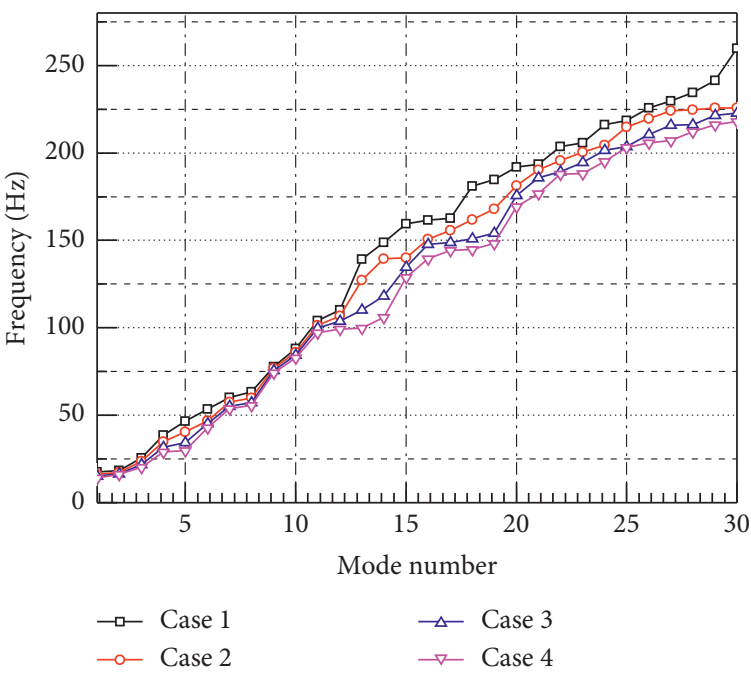

FIGURE 13: The first thirty natural frequencies for different numbers of shear studs.

TABLE 1: Various cases to examine the role of the rib spacing in the structural noise.

\begin{tabular}{lccccccc}
\hline Case & Case 1 & Case 2 & Case 3 & Case 4 & Case 5 & Case 6 & Case 7 \\
\hline Spacing $(\mathrm{mm})$ & 2125.00 & 1062.50 & 531.25 & 1415.00 & 850.00 & - & - \\
Layout & - & - & - & - & - & 700 & 700 \\
\hline
\end{tabular}

The obtained results reveal that the noise reduction is more influential for the case of uniform distribution of the ribs in the midspan than the case of the uniform distribution in the whole span. The difference between the total sound power level of Case 1 and that of Case 6 is about $4.3 \mathrm{~dB}$. Nevertheless, the variations of the spacing and position of the ribs have no obvious influence on the sound power spectrum. 

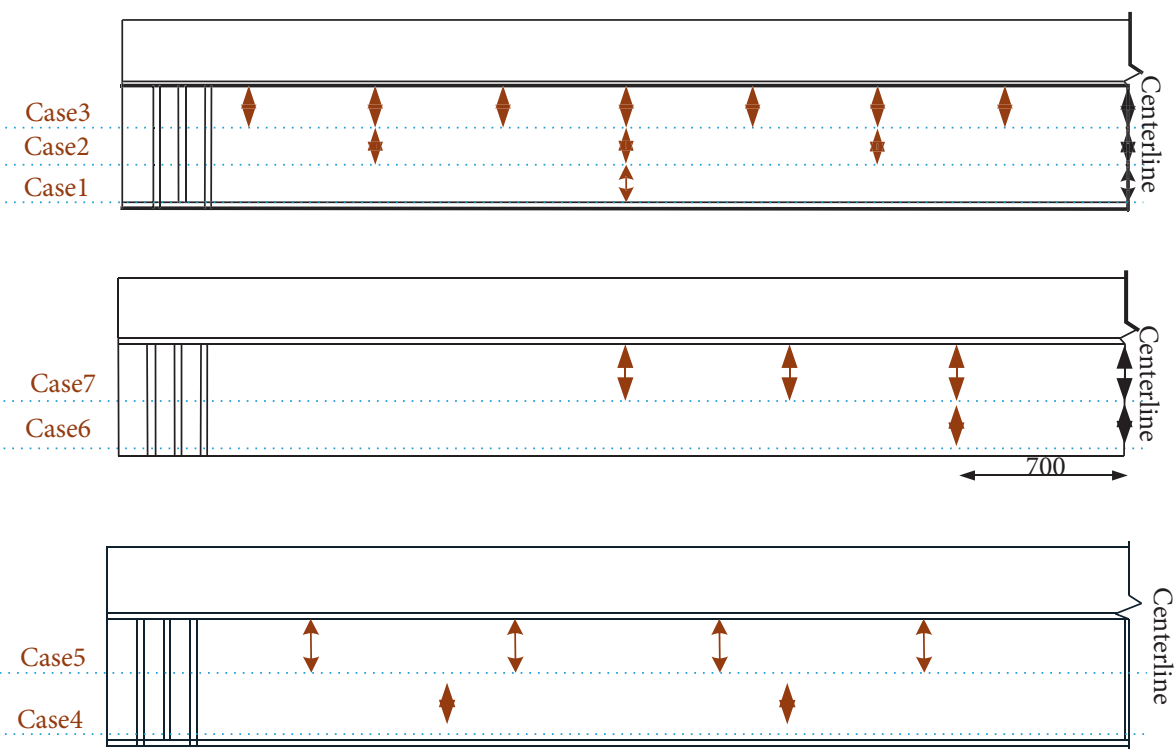

FIGURE 14: Various layouts of the ribs.

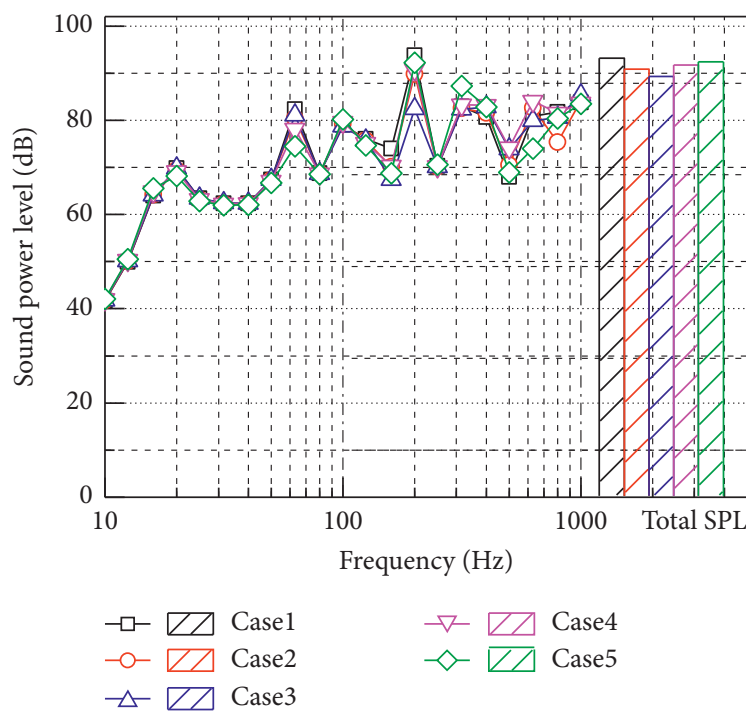

(a)

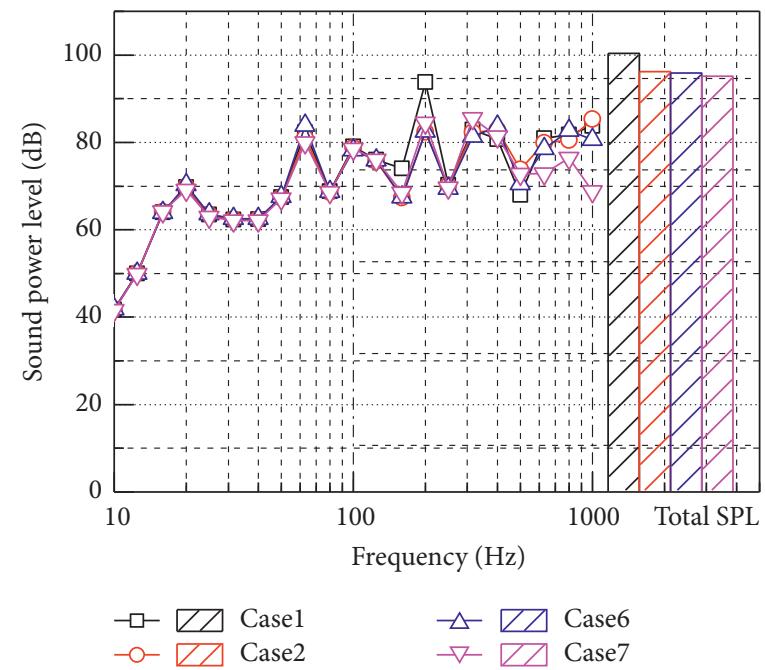

(b)

FIgURE 15: Variation of the sound power level with the characteristics of rib distribution. (a) Variation of the sound power level for various numbers of the ribs. (b) Variation of the sound power level for various arrangements of the ribs.

\section{Conclusions}

The vibrational noise of SCCPB is experimentally and theoretically examined by the hammering test. The predicted vibration and noise results by the numerical simulations are compared with the measured values of the concrete deck, steel beam web, and lower flange at the midspan. The numerical results are in good agreement with those of the test, proving the accuracy of the theoretical model. The excitation force of magnitude $100 \mathrm{~N}$ in the frequency range of $10-1000 \mathrm{~Hz}$ is exerted at the span center of the model concrete deck. Through the analysis of the design parameters of the SCCPB, the following major results, which provide specific ideas for the noise reduction design of practical engineering, are obtained:
(1) The increase of the concrete deck thickness and number of shear studs can reduce the radiated sound power level. The more the number of shear studs, the better the noise reduction effect.

(2) The noise reduction of the rib plate with uniform and dense arrangement in the middle of the span is more influential than the case with uniform and dense arrangement of ribs in the whole span domain.

(3) When the design parameters in this paper are applied to the SCCPB in practical engineering, the structural vibration and sound radiation characteristics will be more complex. Due to the increase of calculation complexity, the BEM has particular limitations in 
solving high-frequency problems. At present, acoustic optimization approaches are required to be further scrutinized.

\section{Data Availability}

The raw data used to support the findings of this study are included within the article and are available from the corresponding author upon request.

\section{Conflicts of Interest}

The authors declare that they have no conflicts of interest.

\section{Acknowledgments}

This study was financially supported by the Fundamental Research Funds for the Central Universities (2021YJS133) and National Natural Science Foundation of China (52178101). The authors would like to express their gratitude to EditSprings (https://www.editsprings.cn) for the expert linguistic services provided.

\section{References}

[1] D. Thompson, Railway Noise and Vibration: Mechanisms, Modeling and Means of control, Elsevier, Oxford, UK, 2009.

[2] O. G. Bewes, D. J. Thompson, C. J. C. Jones, and A. Wang, "Calculation of noise from railway bridges and viaducts: experimental validation of a rapid calculation model," Journal of Sound and Vibration, vol. 293, no. 3-5, pp. 933-943, 2006.

[3] G. Ma, "Analysis of the structure-borne noise of composite steel plate continuous bridge in passenger dedicated line," Journal of Railway Engineering Society, vol. 12, no. 5, pp. 72-76, 2016.

[4] H. L. Richard, Statistical Energy Analysis of Dynamical Systems: Theory and Applications, pp. 65-92, MIT Press, Cambridge, MA, USA, 1975.

[5] Q. Liu, X. Li, X. Zhang, and L. Wenjun, "Numerical prediction and experimental validation of structure-borne noise from a railway composite bridge," Journal of the China Railway Society, vol. 40, no. 6, pp. 120-126, 2018.

[6] X. Li, Q. Liu, L. Song, and X. Zhang, "Prediction of structureborne noise of composite steel truss bridge of high-speed railway," Journal of the China Railway Society, vol. 36, no. 12, pp. 97-103, 2014.

[7] Q. Liu, X. Li, L. Liu, X. Zhang, and R. Song, "Vibration and noise mitigation analysis of railway steel-concrete composite bridge using constrained layer damping," SCIENTIA SINICA Technologica, vol. 48, no. 12, pp. 1392-1400, 2018.

[8] X. Li, Q. Liu, S. Pei, L. Song, and X. Zhang, "Structure-borne noise of railway composite bridge: numerical simulation and experimental validation," Journal of Sound and Vibration, vol. 353, pp. 378-394, 2015.

[9] K. Tang, Study and Analysis of Structural Noise of Continuous Slab Beam Steel-concrete Composite Beam Bridge Based on FESEA Hybrid method, East China Jiaotong University, Nanchang, China, 2019.

[10] M. Saito, I. Sugimoto, and E. Sasaki, "Experimental study on noise reduction effect of installing concrete deck on existing steel girders," International Journal of Steel Structures, vol. 15, no. 1, pp. 205-212, 2015.
[11] Z. Hou, X. He, and Y. Zhang, "Analytical solution to dynamic characteristics of simply-supported steel-concrere composite beams," Journal of the China Railway Society, vol. 36, no. 3, pp. 100-105, 2014.

[12] Z. Hou, X. He, Y. Wang, and Y. Zhang, "Dynamic reduction coefficients for a steel-concrete composite beam," Journal of Vibration and Shock, vol. 34, no. 4, pp. 74-81, 2015.

[13] Z. Chao, H. Xu, and D. Wen, "Study on dynamic characteristics of composite beams considering stiffness method," Science \& Technology Association Forum, vol. 2, pp. 12-13, 2009.

[14] W. Feng, Q. Li, and C. Yang, "Analysis of dynamic characteristics of composite steel-concrete beams," in Proceedings of the 19th national conference on Structural Engineering, no. I, pp. 479-482, HangZhou, China, 2010.

[15] S. Ma, M. Li, Y. Guo, and B. Safaei, "Field test and research on shield cutting pile penetrating cement soil single pile composite foundation," Geomechanics and Engineering, vol. 23, no. 6, pp. 513-521, 2020.

[16] Y. Wang, V. Ermilov, S. Strigin, and B. Safaei, "Multilevel modeling of the mechanical properties of graphene nanocomposites/polymer composites," Microsystem Technologies, vol. 27, no. 12, pp. 4241-4251, 2021.

[17] B. Safaei, A. M. Fattahi, and F. Chu, "Finite element study on elastic transition in platelet reinforced composites," Microsystem Technologies, vol. 24, no. 6, pp. 2663-2671, 2018.

[18] P. Ghanati and B. Safaei, "Elastic buckling analysis of polygonal thin sheets under compression," Indian Journal of Physics, vol. 93, no. 1, pp. 47-52, 2019.

[19] B. Safaei, "The effect of embedding a porous core on the free vibration behavior of laminated composite plates," Steel and Composite Structures, vol. 35, no. 5, pp. 659-670, 2021.

[20] X. Li, L. Song, and X. Zhang, "Study on vibration transmission characteristics of high-speed railway simply-supported boxgirders based on in-situ hammer excitation test," China Civil Engineering Journal, vol. 49, no. 5, pp. 120-128, 2016.

[21] K. Luo and X. Lei, "A study of modeling experiments of the vibration behavior of elevated railway box girder," Journal of Vibration and Control, vol. 25, no. 5, pp. 984-995, 2019.

[22] K. Li, N. Zhang, and X. He, "Analysis on structure-borne noise of $32 \mathrm{~m}$ simply-supported tough girder bridge," China Railway Science, vol. 36, no. 4, pp. 52-59, 2015.

[23] X. Zhang, X. Wang, and R. Liu, "Vibro-acoustic characteristics of U-rib stiffened slabs," China Journal of Highway and Transport, vol. 33, no. 7, pp. 76-85, 020. 